\title{
Variables associated with administration of analgesia, nurse-initiated analgesia and early analgesia in the emergency department
}

\author{
David McD Taylor, ${ }^{1}{ }^{1}$ Jessie Chen, ${ }^{1}$ Munad Khan, ${ }^{1}$ Marina Lee, ${ }^{1}$ Mani Rajee, ${ }^{1}$ \\ Michael Yeoh, ${ }^{1}$ Joanna R Richardson, ${ }^{1}$ Antony M Ugoni ${ }^{3}$
}

${ }^{1}$ Department of Emergency Medicine, Austin Health, Heidelberg, Victoria, Australia ${ }^{2}$ Department of Medicine, University of Melbourne, Parkville, Victoria, Australia ${ }^{3}$ Department of Physiotherapy, University of Melbourne, Parkville, Victoria, Australia

\section{Correspondence to}

Professor David Taylor, Emergency Department, Austin Health, PO Box 5555 , Heidelberg, VIC 3084, Australia;

David.Taylor@austin.org.au

Received 11 May 2016 Revised 5 October 2016 Accepted 7 October 2016 Published Online First 27 October 2016

CrossMark

To cite: Taylor DMD, Chen J, Khan $\mathrm{M}$, et al. Emerg Med J 2017;34:1319.

\section{ABSTRACT}

Objective To determine the patient and clinical variables associated with administration of any analgesia, nurse-initiated analgesia (NIA, prescribed and administered by a nurse) and early analgesia (within 30 min of presentation).

Methods We undertook a retrospective cohort study of patients who presented to a metropolitan ED in Melbourne, Australia, during July and August, 2013. The ED has an established NIA programme. Patients were included if they were aged 18 years or more and presented with a painful complaint. The study sample was randomly selected from a list of all eligible patients. Data were extracted electronically from the ED records and by explicit extraction from the medical record. Logistic regression models were constructed to assess associations with the three binary study end points.

Results 1289 patients were enrolled. Patients were less likely to receive any analgesia if they presented 08:00$15: 59$ hours (OR $0.67,95 \% \mathrm{Cl} 0.46$ to 0.98 ) or $16: 00$ 24:00 hours (OR $0.55,95 \% \mathrm{Cl} 0.37$ to 0.80 ) were triage category 5 (OR $0.20,95 \% \mathrm{Cl} 0.08$ to 0.49$)$ or required an interpreter $(\mathrm{OR} 0.34,95 \% \mathrm{Cl} 0.14$ to 0.86$)$. Patients were less likely to receive NIA or early analgesia if they were aged 56 years or more (OR 0.70 and 0.63 ; OR 0.57 and 0.21 , respectively) or if they had received ambulance analgesia (OR $0.59,95 \% \mathrm{Cl} 0.36$ to 0.95 ; OR $0.38,95 \% \mathrm{Cl} 0.20$ to 0.74 , respectively).

Conclusions Patients who present during the daytime, have a triage category of 5 or require an interpreter are less likely to receive analgesia. Older patients and those who received ambulance analgesia are less likely to receive NIA or early analgesia.

\section{INTRODUCTION}

A number of reports have highlighted widespread undertreatment of ED patients with pain. ${ }^{1}$ Although the extent and degree of this problem has recently been challenged, ${ }^{2}$ it is likely that considerable scope remains for improvement in ED pain management practice. Initiatives to improve pain management have included staff training, ${ }^{3}$ mandatory recording of pain scores, ${ }^{4}$ nurse-initiated analgesia (NIA, prescribed and administered by a nurse), ${ }^{5}$ time-to-analgesia performance indicators ${ }^{6}$ and the provision of 'adequate analgesia' as measured by changes in the pain score. ${ }^{78}$ The overall aim of these initiatives is to provide early, safe and effective analgesia to those with valid indications.

Despite these initiatives, there are recent reports that considerable proportions of patients do not

\section{Key messages}

What is already known on this subject?

- Most research reports indicate that pain management in the ED could be improved.

- Initiatives aiming to improve pain management do not always lead to the provision of analgesia when it is indicated.

\section{What this study adds?}

- The study identified variables associated with the nature of analgesia provided.

- Older patients are less likely to receive nurse-initiated analgesia (prescribed and administered by a nurse) or early analgesia (within 30 min of presentation).

- Patients requiring an interpreter are less likely to receive any analgesia.

- These patient groups are at risk of poor pain management and initiatives to mitigate this risk are required.

receive analgesia in the ED. ${ }^{9}$ For patients who do receive analgesia, it is often administered well after presentation to the ED. ${ }^{4} 910$ Timely analgesia is a responsibility of ED staff and is expected by ED patients within $30 \mathrm{~min}^{4}{ }^{41}$ These expectations informed the development of NIA programmes which provide an opportunity for treatment at triage or shortly after admission to an ED cubicle. In some UK, USA, Irish and Australasian EDs, nursing staff are credentialled to administer oral and parenteral analgesia, including opioids, for a wide range of presenting complaints and without a prescription from an ED doctor. ${ }^{5}$ It has been reported that NIA promotes more timely analgesia administration, ${ }^{12}$ increases pain management satisfaction $^{13}$ and affects the patients' perceptions of the quality of their pain management. ${ }^{14}$

In our ED, credentialled nursing staff are able to administer NIA to patients who are aged 14 years or more (no upper limit), weigh $>40 \mathrm{~kg}$ and who have a triage category $2-5$. Patients may not receive NIA if they have a suspected abdominal aortic aneurysm or ischaemic chest pain, a headache or head injury, are pregnant, lactating, intoxicated or acutely confused, are taking regular opioid medication or are thought to be drug seeking. The nurses are not required to administer NIA if, for any reason, they are concerned about its safety. 
Paracetamol \pm codeine, ibuprofen, oxycodone and morphine can all be administered within the NIA guidelines.

We hypothesise that there are patient characteristics and/or ED system variables that act as barriers to the administration of analgesia, NIA and early analgesia. This study aimed to determine these barriers in order to inform further research and the development of intervention initiatives aimed at mitigating their effect.

\section{METHODS}

\section{Study design and setting}

We undertook a retrospective cohort study of patients who presented to a single ED in Melbourne, Australia, during July and August 2013. The ED is a metropolitan, tertiary referral, mixed (adult and paediatric) centre with an annual census of approximately 70000 patients. The study was approved by the hospital's Human Research Ethics Committee.

\section{Study population}

Patients were eligible for inclusion if they were aged 18 years or more and presented during the study period for management of a painful complaint (Triage Pain Score $>0$ on a $0-10$ Verbal Numerical Pain Rating Scale ${ }^{15}$ There were no exclusion criteria.

A list of all patients who presented to the ED during the study period was generated from the ED MedTrak system and saved as an Excel spreadsheet. All patients in our ED are assigned a pain score at triage. After removing patients aged under 18 years and those with no pain, patients were randomly sorted using the Excel RAND function. The 1300 patients at the top of this sorted list comprised the final data set for analysis (figure 1).

\section{Data collection}

Most data were extracted electronically directly from the medical record: patient age, gender, day and time of

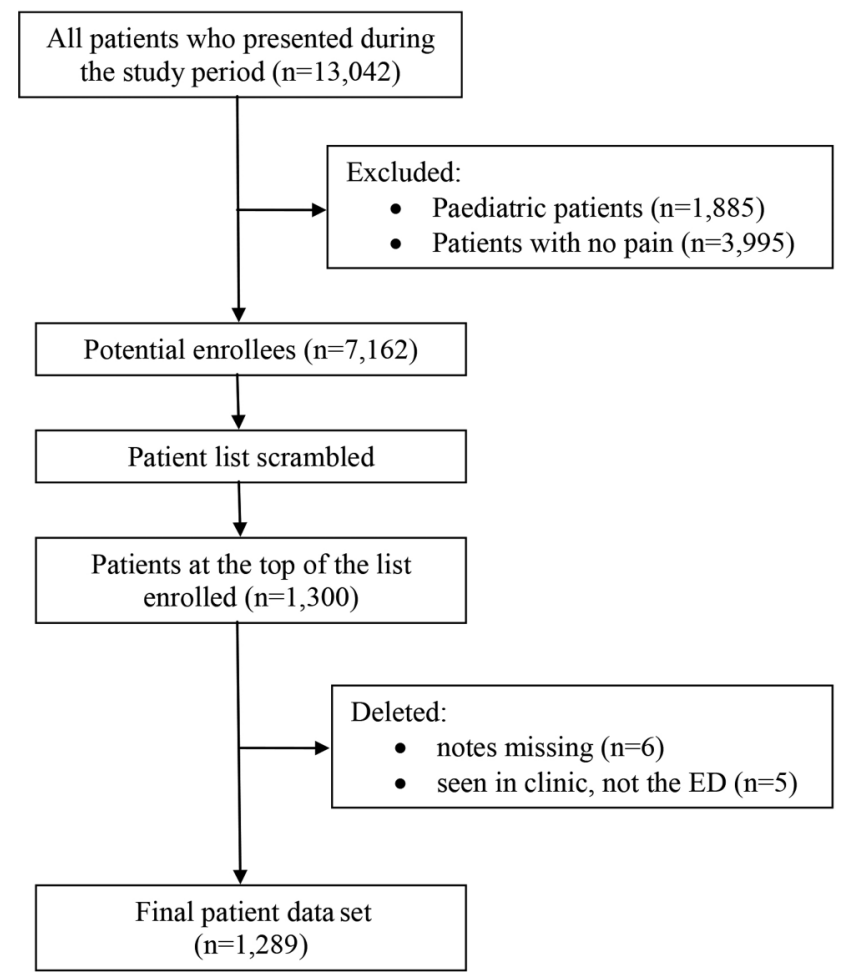

Figure 1 Patient flow through the study. presentation, triage category, pain score, presenting complaint and need for an interpreter. Data on analgesia administered by the ambulance service were also collected. Mild, moderate or severe pain were pain scores of $1-3,3-7$ and $8-10$, respectively. ${ }^{16}$ It is compulsory to record these data at triage. Explicit medical record reviews were undertaken by six of the investigators to extract the remaining data (details of analgesia given in an ambulance and the ED, patient ethnicity and their preferred language). No hard copy data collection sheets were employed and all data were entered directly into the study electronic data set. The principal investigator then reviewed the medical records of $10 \%$ of enrolled patients. Fewer than five data extraction errors were found (all errors of omission) and these were all corrected by the principal investigator.

\section{Outcomes}

The study outcomes were the provision of any analgesia in the ED, NIA and early analgesia (within $30 \mathrm{~min}$ of presentation). NIA and early analgesia are considered sufficiently different end points. There is likely to be some overlap between the groups as NIA administered at triage will result in early analgesia. However, NIA can be administered at any time during the patient's stay and is not necessarily early analgesia. In this study, analgesia included simple and opioid pain killers, glyceryl trinitrate, antacids, nitrous oxide, migraine-specific medication and local anaesthesia.

\section{Data analysis}

For two patient variable classifications, a $10 \%$ difference in the proportions who received a study outcome of interest was considered clinically significant, for example, $45 \%$ of men versus $55 \%$ of women (difference in proportions 10\%) received analgesia in the ED. In order to demonstrate a difference of $10 \%$, at least 543 patients were needed in each group (ratio of numbers in each group 1:1, level of significance 0.05 , two-sided, power $0.9)$. The total of 1086 was rounded up to 1300 to account for expected ratio differences and multiple variable classifications.

Logistic regression was used to determine which relevant patient variables were associated with each of the three study end points. Variable categories were determined a priori and initially explored using univariate analyses. Subsequently, all variables were included in multivariate analyses as each had significant or near significant associations with at least one outcome variable. ORs with 95\% CIs were calculated for both univariate and multivariate analyses. Intercooled Stata V.6.0 for Windows 98/95/NT, Stata Corporation, College Station, Texas, USA was employed for the regression analyses.

\section{RESULTS}

During the study period $7162(64.2 \%)$ adult patients presented to the ED with pain. Of these, 1289 patients were randomly selected and comprised the final data set (figure 1). The sexes were equally represented although fewer older patients (aged 76 years and above) were enrolled. Overall, the majority of patients identified as Australian, New Zealand or British ethnicity, presented between 08:00 and 24:00, had a non-urgent triage category (3-5) and mild (1-3) to moderate (4-7) pain. ${ }^{17}$ English was the preferred language for the large majority and few patients required an interpreter.

Overall, $745(57.8 \%)$ patients received any type of analgesia while they were in the ED (table 1). Patients were more likely to receive any analgesia if they had moderate-severe pain or had received ambulance analgesia. They were less likely if they presented between 08:00 and 24:00 (compared with patients 
Table 1 Variables associated with the administration of analgesia in the ED

\begin{tabular}{|c|c|c|c|c|c|c|}
\hline & \multicolumn{2}{|c|}{ ED analgesia } & \multicolumn{2}{|c|}{ Univariate } & \multicolumn{2}{|c|}{ Multivariate } \\
\hline & Not given & Given & OR & $95 \% \mathrm{Cl}$ & OR & $95 \% \mathrm{Cl}$ \\
\hline \multicolumn{7}{|l|}{ Sex } \\
\hline Male & 277 & 366 & 1 & & 1 & \\
\hline Female & 267 & 379 & 1.07 & 0.86 to 1.34 & 1.14 & 0.89 to 1.46 \\
\hline \multicolumn{7}{|l|}{ Age, years } \\
\hline $18-35$ & 159 & 245 & 1 & & 1 & \\
\hline $36-55$ & 145 & 219 & 0.98 & 0.73 to 1.31 & 1.00 & 0.73 to 1.38 \\
\hline $56-75$ & 147 & 184 & 0.81 & 0.60 to 1.09 & 0.88 & 0.62 to 1.23 \\
\hline 76 and above & 93 & 97 & 0.68 & 0.48 to 0.96 & 0.88 & 0.59 to 1.31 \\
\hline \multicolumn{7}{|l|}{ Time of presentation } \\
\hline 00:00-07:59 & 61 & 131 & 1 & & 1 & \\
\hline 08:00-15:59 & 251 & 336 & 0.62 & 0.44 to 0.88 & 0.67 & 0.46 to 0.98 \\
\hline 16:00-23:59 & 232 & 278 & 0.56 & 0.39 to 0.79 & 0.55 & 0.37 to 0.80 \\
\hline \multicolumn{7}{|l|}{ Day of presentation } \\
\hline Weekday & 378 & 540 & 1 & & 1 & \\
\hline Weekend & 166 & 205 & 0.86 & 0.68 to 1.10 & 0.86 & 0.65 to 1.12 \\
\hline \multicolumn{7}{|l|}{ Presenting complaint } \\
\hline Abdominal, urological & 79 & 192 & 1 & & 1 & \\
\hline Trauma & 74 & 94 & 0.52 & 0.35 to 0.78 & 0.77 & 0.49 to 1.20 \\
\hline Chest pain & 76 & 91 & 0.49 & 0.33 to 0.74 & 0.50 & 0.31 to 0.82 \\
\hline Musculoskeletal & 46 & 109 & 0.97 & 0.63 to 1.50 & 1.31 & 0.81 to 2.12 \\
\hline Other & 269 & 259 & 0.40 & 0.29 to 0.54 & 0.56 & 0.40 to 0.78 \\
\hline \multicolumn{7}{|l|}{ Triage category* } \\
\hline $2 \dagger$ & 75 & 122 & 1 & & 1 & \\
\hline 3 & 210 & 355 & 1.04 & 0.74 to 1.45 & 0.95 & 0.63 to 1.44 \\
\hline 4 & 227 & 259 & 0.70 & 0.50 to 0.98 & 0.73 & 0.47 to 1.14 \\
\hline 5 & 32 & 9 & 0.17 & 0.08 to 0.38 & 0.20 & 0.08 to 0.49 \\
\hline \multicolumn{7}{|l|}{ Triage Pain Scoreł } \\
\hline 1-3 (mild) & 301 & 198 & 1 & & 1 & \\
\hline 4-7 (moderate) & 215 & 386 & 2.73 & 2.13 to 3.49 & 2.62 & 2.02 to 3.40 \\
\hline 8-10 (severe) & 28 & 161 & 8.74 & 5.63 to 13.57 & 7.21 & 4.52 to 11.51 \\
\hline \multicolumn{7}{|l|}{ Ethnicity } \\
\hline Australian, NZ, Brit & 198 & 290 & 1 & & 1 & \\
\hline European & 57 & 55 & 0.66 & 0.44 to 0.99 & 0.83 & 0.51 to 1.34 \\
\hline Asian & 25 & 31 & 0.85 & 0.49 to 1.48 & 1.22 & 0.65 to 2.30 \\
\hline Other & 10 & 16 & 1.09 & 0.49 to 2.46 & 0.88 & 0.36 to 2.11 \\
\hline Missing & 254 & 353 & 0.95 & 0.74 to 1.21 & 1.04 & 0.80 to 1.36 \\
\hline \multicolumn{7}{|c|}{ Preferred language other than English } \\
\hline No & 494 & 700 & 1 & & 1 & \\
\hline Yes & 50 & 45 & 0.64 & 0.42 to 0.97 & 1.22 & 0.62 to 2.40 \\
\hline \multicolumn{7}{|l|}{ Interpreter required } \\
\hline No & 512 & 726 & 1 & & 1 & \\
\hline Yes & 32 & 19 & 0.42 & 0.23 to 0.75 & 0.34 & 0.14 to 0.86 \\
\hline \multicolumn{7}{|l|}{ Ambulance analgesia } \\
\hline Not given & 500 & 647 & 1 & & 1 & \\
\hline Given & 44 & 98 & 1.72 & 1.18 to 2.50 & 2.30 & 1.50 to 3.51 \\
\hline
\end{tabular}

presenting at night), had pain from 'other' (miscellaneous) causes, had a triage category of 5 or required an interpreter.

NIA was administered to 419 patients: $32.5 \%$ of all patients and $56.2 \%$ of patients who received any analgesia (table 2). Patients were more likely to receive NIA if they had moderatesevere pain (compared with those with mild pain) or were triage category 3 or 4 . They were less likely if they were aged 56 years or more, had pain from an 'other' cause or had received ambulance analgesia.

Two hundred and forty-eight (19.2\%) patients received early analgesia (table 3). Patients were more likely to receive early analgesia if they had severe pain (compared with those with mild pain), were triage category 4 or 5 , or required an interpreter. They were less likely if they were aged 56 years or more, 
Table 2 Variables associated with administration of nurse-initiated analgesia

\begin{tabular}{|c|c|c|c|c|c|c|}
\hline & \multicolumn{2}{|c|}{ Nurse-initiated analgesia } & \multicolumn{2}{|c|}{ Univariate } & \multicolumn{2}{|c|}{ Multivariate } \\
\hline & Not given & Given & OR & $95 \% \mathrm{Cl}$ & OR & $95 \% \mathrm{Cl}$ \\
\hline \multicolumn{7}{|l|}{ Sex } \\
\hline Male & 431 & 212 & 1 & & 1 & \\
\hline Female & 439 & 207 & 0.96 & 0.76 to 1.21 & 1.01 & 0.78 to 1.31 \\
\hline \multicolumn{7}{|l|}{ Age, years } \\
\hline $18-35$ & 243 & 161 & 1 & & 1 & \\
\hline $36-55$ & 236 & 128 & 0.82 & 0.61 to 1.10 & 0.87 & 0.63 to 1.21 \\
\hline $56-75$ & 243 & 88 & 0.55 & 0.40 to 0.75 & 0.70 & 0.49 to 0.99 \\
\hline 76 and above & 148 & 42 & 0.43 & 0.29 to 0.64 & 0.63 & 0.40 to 0.97 \\
\hline \multicolumn{7}{|l|}{ Time of presentation } \\
\hline 00:00-07:59 & 121 & 71 & 1 & & 1 & \\
\hline 08:00-15:59 & 400 & 187 & 0.80 & 0.57 to 1.12 & 0.82 & 0.56 to 1.20 \\
\hline $16: 00-23: 59$ & 349 & 161 & 0.79 & 0.56 to 1.11 & 0.76 & 0.52 to 1.12 \\
\hline \multicolumn{7}{|l|}{ Day of presentation } \\
\hline Weekday & 614 & 304 & 1 & & 1 & \\
\hline Weekend & 256 & 115 & 0.91 & 0.70 to 1.18 & 0.90 & 0.68 to 1.20 \\
\hline \multicolumn{7}{|l|}{ Presenting complaint } \\
\hline Abdominal, urological & 153 & 118 & 1 & & 1 & \\
\hline Trauma & 107 & 61 & 0.74 & 0.50 to 1.10 & 0.97 & 0.62 to 1.50 \\
\hline Chest pain & 127 & 40 & 0.41 & 0.27 to 0.63 & 0.86 & 0.52 to 1.42 \\
\hline Musculoskeletal & 81 & 74 & 1.18 & 0.80 to 1.76 & 1.33 & 0.85 to 2.08 \\
\hline Other & 402 & 126 & 0.41 & 0.30 to 0.56 & 0.55 & 0.39 to 0.78 \\
\hline \multicolumn{7}{|l|}{ Triage category* } \\
\hline $2 \dagger$ & 154 & 43 & 1 & & 1 & \\
\hline 3 & 364 & 201 & 1.98 & 1.35 to 2.89 & 1.94 & 1.23 to 3.04 \\
\hline 4 & 318 & 168 & 1.89 & 1.29 to 2.78 & 2.03 & 1.25 to 3.30 \\
\hline 5 & 34 & 7 & 0.74 & 0.31 to 1.78 & 0.88 & 0.33 to 2.29 \\
\hline \multicolumn{7}{|l|}{ Triage Pain Score $\ddagger$} \\
\hline $1-3$ & 411 & 88 & 1 & & 1 & \\
\hline $4-7$ & 377 & 224 & 2.78 & 2.09 to 3.68 & 2.53 & 1.88 to 3.42 \\
\hline $8-10$ & 82 & 107 & 6.09 & 4.23 to 8.81 & 5.71 & 3.77 to 8.64 \\
\hline \multicolumn{7}{|l|}{ Ethnicity } \\
\hline Australian, NZ, Brit & 349 & 139 & 1 & & 1 & \\
\hline European & 94 & 18 & 0.48 & 0.28 to 0.83 & 0.74 & 0.40 to 1.34 \\
\hline Asian & 40 & 16 & 1.00 & 0.54 to 1.85 & 1.29 & 0.66 to 2.52 \\
\hline Other & 19 & 7 & 0.93 & 0.38 to 2.25 & 0.93 & 0.36 to 2.43 \\
\hline Missing & 368 & 239 & 1.63 & 1.26 to 2.10 & 1.99 & 1.50 to 2.63 \\
\hline \multicolumn{7}{|c|}{ Preferred language other than English } \\
\hline No & 797 & 397 & 1 & & 1 & \\
\hline Yes & 73 & 22 & 0.61 & 0.37 to 0.99 & 0.98 & 0.46 to 2.09 \\
\hline \multicolumn{7}{|l|}{ Interpreter required } \\
\hline No & 830 & 408 & 1 & & 1 & \\
\hline Yes & 40 & 11 & 0.56 & 0.28 to 1.10 & 0.65 & 0.23 to 1.86 \\
\hline \multicolumn{7}{|l|}{ Ambulance analgesia } \\
\hline Not given & 755 & 392 & 1 & & 1 & \\
\hline Given & 115 & 27 & 0.45 & 0.29 to 0.70 & 0.59 & 0.36 to 0.95 \\
\hline
\end{tabular}

had pain from an 'other' cause, or if they had received ambulance analgesia.

\section{DISCUSSION}

During the study period, almost two-thirds of all adult patients presented to the ED with a painful complaint. Although this is less than the estimate of three quarters reported by Cordell et $a l,{ }^{18}$ it indicates the high prevalence of pain among $\mathrm{ED}$ patients. This highlights the need for adequate pain management strategies especially as effective management is associated with improved patient satisfaction. ${ }^{19}$

More than half of patients (57.8\%) received analgesia. While this proportion is low, it is consistent with other reports. ${ }^{20}$ Approximately a third of all patients (32.5\%) received NIA. These patients represented a substantial proportion of all patients who received analgesia and suggests that the nursing 
Table 3 Variables associated with administration of analgesia less than $30 \mathrm{~min}$ from presentation

\begin{tabular}{|c|c|c|c|c|c|c|}
\hline & \multicolumn{2}{|c|}{ Analgesia $<30 \mathrm{~min}$} & \multicolumn{2}{|c|}{ Univariate } & \multicolumn{2}{|c|}{ Multivariate } \\
\hline & No & Yes & OR & $95 \% \mathrm{Cl}$ & OR & $95 \% \mathrm{Cl}$ \\
\hline \multicolumn{7}{|l|}{ Sex } \\
\hline Male & 233 & 133 & 1 & & 1 & \\
\hline Female & 261 & 115 & 0.77 & 0.57 to 1.05 & 0.88 & 0.63 to 1.24 \\
\hline \multicolumn{7}{|l|}{ Age, years } \\
\hline $18-35$ & 141 & 103 & 1 & & 1 & \\
\hline $36-55$ & 137 & 81 & 0.81 & 0.56 to 1.18 & 0.77 & 0.51 to 1.16 \\
\hline $56-75$ & 133 & 50 & 0.51 & 0.34 to 0.78 & 0.57 & 0.36 to 0.90 \\
\hline 76 and above & 83 & 14 & 0.23 & 0.12 to 0.43 & 0.21 & 0.10 to 0.41 \\
\hline \multicolumn{7}{|l|}{ Time of presentation } \\
\hline 00:00-07:59 & 88 & 43 & 1 & & 1 & \\
\hline 08:00-15:59 & 208 & 127 & 1.25 & 0.82 to 1.91 & 1.33 & 0.83 to 2.14 \\
\hline $16: 00-23: 59$ & 198 & 78 & 0.81 & 0.51 to 1.26 & 0.78 & 0.48 to 1.28 \\
\hline \multicolumn{7}{|l|}{ Day of presentation } \\
\hline Weekday & 362 & 176 & 1 & & 1 & \\
\hline Weekend & 132 & 72 & 1.12 & 0.80 to 1.57 & 1.06 & 0.72 to 1.54 \\
\hline \multicolumn{7}{|l|}{ Presenting complaint } \\
\hline Abdominal, urological & 111 & 80 & 1 & & 1 & \\
\hline Trauma & 57 & 36 & 0.88 & 0.53 to 1.45 & 0.95 & 0.53 to 1.69 \\
\hline Chest pain & 68 & 23 & 0.47 & 0.27 to 0.82 & 0.92 & 0.48 to 1.76 \\
\hline Musculoskeletal & 61 & 48 & 1.09 & 0.68 to 1.76 & 0.96 & 0.56 to 1.64 \\
\hline Other & 197 & 61 & 0.43 & 0.29 to 0.65 & 0.45 & 0.29 to 0.71 \\
\hline \multicolumn{7}{|l|}{ Triage category* } \\
\hline $2+$ & 93 & 29 & 1 & & 1 & \\
\hline 3 & 242 & 111 & 1.47 & 0.92 to 2.36 & 1.27 & 0.72 to 2.22 \\
\hline 4 & 156 & 102 & 2.10 & 1.29 to 3.41 & 2.06 & 1.12 to 3.80 \\
\hline 5 & 3 & 6 & 6.41 & 1.51 to 27.27 & 10.96 & 2.12 to 56.60 \\
\hline \multicolumn{7}{|l|}{ Triage Pain Scoreł } \\
\hline $1-3$ & 155 & 42 & 1 & & 1 & \\
\hline $4-7$ & 251 & 133 & 1.96 & 1.31 to 2.92 & 1.53 & 0.99 to 2.38 \\
\hline $8-10$ & 88 & 73 & 3.06 & 1.93 to 4.85 & 2.55 & 1.50 to 4.35 \\
\hline \multicolumn{7}{|l|}{ Ethnicity } \\
\hline Australian, NZ, Brit & 199 & 89 & 1 & & 1 & \\
\hline European & 44 & 11 & 0.56 & 0.28 to 1.13 & 0.75 & 0.34 to 1.67 \\
\hline Asian & 22 & 9 & 0.91 & 0.40 to 2.07 & 0.65 & 0.26 to 1.62 \\
\hline Other & 12 & 4 & 0.75 & 0.23 to 2.37 & 0.59 & 0.16 to 2.16 \\
\hline Missing & 217 & 135 & 1.39 & 1.00 to 1.93 & 1.49 & 1.04 to 2.13 \\
\hline \multicolumn{7}{|c|}{ Preferred language other than English } \\
\hline No & 462 & 235 & 1 & & 1 & \\
\hline Yes & 32 & 13 & 0.80 & 0.41 to 1.55 & 0.62 & 0.20 to 1.96 \\
\hline \multicolumn{7}{|l|}{ Interpreter required } \\
\hline No & 484 & 239 & 1 & & 1 & \\
\hline Yes & 10 & 9 & 1.82 & 0.73 to 4.55 & 4.97 & 1.07 to 23.11 \\
\hline \multicolumn{7}{|l|}{ Ambulance analgesia } \\
\hline Not given & 409 & 235 & 1 & & 1 & \\
\hline Given & 85 & 13 & 0.27 & 0.15 to 0.49 & 0.38 & 0.20 to 0.74 \\
\hline
\end{tabular}

staff are comfortable in administering analgesia in accordance with their NIA guideline. Approximately a fifth of patients (19.2\%) received early analgesia. While this proportion is low, it is encouraging that those with severe pain were more likely to receive early analgesia. Overall, approximately a third of patients who received analgesia received it early. This is more than the $24 \%$ reported by Hansen et al. ${ }^{10}$ While this is encouraging, there is scope for considerable improvement.
A number of other reports have found that elderly patients are less likely to receive analgesia. ${ }^{21}$ However, our study and that reported by Hwang et $a l^{22}$ do not provide this evidence. Our finding that patients aged 56 years or more were less likely to receive NIA or early analgesia is of concern as this may indicate a lower quality of pain management. Others have also reported that older patients wait longer for analgesia. ${ }^{9}{ }^{21}$ Cinar et $a l^{9}$ also reported longer waiting times for analgesia among 
the elderly although this association was not significant after adjusting for initial pain scores. We did adjust for Triage Pain Score and other confounding variables and the negative association between age and early analgesia remained. The reasons for these findings are not known although patient variables (eg, stoicism or propensity to refuse analgesia) and staff attitudes (eg, concern about adverse events and coexistent regular medications) may contribute.

Patients who presented between 08:00 and 24:00 were less likely to receive analgesia although the administration of NIA and early analgesia were not affected. The regression analyses likely accounted for a range of confounding variables (eg, differing presenting complaint profiles at night). However, other potentially confounding variables were not collected and addressed (eg, staffing levels and experience, busyness of ED and duration of pain).

Patients who presented with their cause of pain in the 'other' category were less likely to receive analgesia, NIA or early analgesia. The 'other' category was large and diverse and, although not apparent from the raw data, may have contained specific causes that could be adequately treated without analgesia and where NIA is not allowed, for example, migraine. This possibility may also be the reason that patients with chest pain were less likely to receive analgesia. Some of these patients had ischaemic chest pain that was likely to have been adequately treated with other specific non-analgesic medication, for example, nitroglycerine.

Overall, the less urgent the triage category, the more likely patients were to receive analgesia. Patients with moderate/severe pain were more likely to receive analgesia and NIA and those with severe pain were more likely to receive early analgesia. These findings are consistent with triage guidelines in which pain is a variable used to determine the triage category. Patients in triage categories 4 and 5 were more likely to receive early analgesia. It is likely that many of these patients were managed in the 'fast track' area of the ED and could be managed quickly with oral analgesia.

Neither preferred language nor ethnicity was associated with any of the study outcomes. These findings suggest a lack of discrimination based upon these variables. This is encouraging although not consistent with other reports of ethnic discrimination. ${ }^{23}$ However, patients who required an interpreter were less likely to receive analgesia. This may relate to communication difficulties and a lesser ability for staff to adequately assess the patient's pain. If these patients did receive analgesia, they were more likely to receive it early. This suggests that clinical variables, rather than communication, indicated the need for early analgesia administration.

Patients who were given analgesia in an ambulance were more likely to also receive analgesia in the ED. Assuming the underlying cause for the pain remains constant throughout the ED stay, it is reasonable to expect that additional analgesia would be required once the ambulance analgesia began to wear off. However, patients given ambulance analgesia were less likely to receive NIA or early analgesia. This is not surprising as the ambulance analgesia would likely be taking effect upon arrival at the ED and there may be a reluctance to administer more at triage or early in the ED stay.

This study has identified a number of variables associated with the administration of analgesia. While the proportion appears low, it does not necessarily mean that the pain management was suboptimal. Indeed, when ED patients are offered analgesia, it has been reported that nearly half of them decline it. ${ }^{24}$ This may relate to tolerability of the pain, the need to leave the ED quickly or drive home, or the fear of side effects or addiction. ${ }^{2}$ Green $^{2}$ also highlights other legitimate reasons why patients do not receive analgesia including contraindications to opioids, drug seeking, the availability of suitable non-analgesic medication and treatments (eg, antiemetics, reassurance, oxygen, hydration, limb splinting).

Our study was not designed to determine the reasons why patients did not receive analgesia. Further research is recommended to determine these reasons, especially why patients refuse analgesia. These reasons may be complex and affected by the patient's subjective experience of pain and a range of psychosocial, behavioural and cultural factors. ${ }^{23}$

A significant association between patient satisfaction and analgesic administration has been reported. ${ }^{19}$ Timely analgesia is also important. However, simple interventions such as patient reassurance may be valued even more. ${ }^{25}$ Further research should concentrate upon patient satisfaction, especially in relation to refusal of analgesics, time to analgesia, the perceived adequacy of analgesia and the use of non-medication modes of pain management.

\section{Limitations}

Only data on a sample of patients were analysed. However, as the sample was large and randomly selected from all hours of the day and days of the week it is unlikely that selection bias substantially affected the results.

As a retrospective study, all data were collected for clinical and administrative purposes. While there is the potential for this to have introduced measurement bias, there is no reason to believe that the data were inaccurate. Also, data extraction was explicit and the data extraction accuracy exercise confirmed its accurate extraction.

The study design precluded collection of data that might have better determined the reasons why some patients did not receive analgesia, NIA or early analgesia. We recommend further studies to better investigate these reasons and the implementation of initiatives to improve these variables.

Language was the only communication variable examined. Other communication variables that may have been associated with the study end points were not collected, for example, dementia, delirium, mental incapacity.

As a substantial proportion of patients did not get analgesia in the ED, this decreased the sample size for the analysis of variables associated with early administration of analgesia. It is possible that the power of this analysis was insufficient to demonstrate some significant associations. As a single centre study, it may not be representative of other EDs and external validity of the findings is questionable.

\section{CONCLUSION}

Patients who present during the daytime, who have a triage category of 5 or who require an interpreter are less likely to receive analgesia. Patients aged 56 years or more and those who received ambulance analgesia are less likely to receive NIA or early analgesia. These patient groups may be at risk of suboptimal pain management. Neither ethnicity nor preferred language was associated with analgesia provision.

Contributors DMCDT, JRR and MY conceived and designed the study, and contributed to the ethics committee (IRB) application. DMcDT supervised the study overall. JC, MK, ML, MR, JRR and MY collected all data. DMcDT cleaned and formatted the data and compiled it into a single data set. DMCDT and AMU undertook the data analysis. All authors contributed to interpretation of the results, and drafting and revision of the manuscript. DMcDT takes responsibility for the paper as a whole.

Competing interests None declared.

Provenance and peer review Not commissioned; externally peer reviewed. 


\section{REFERENCES}

1 Rupp T, Delaney KA. Inadequate analgesia in emergency medicine. Ann Emerg Med 2004;43:494-503.

2 Green SM. There is oligo-evidence for oligoanalgesia. Ann Emerg Med 2012;60:212-14.

3 Decosterd I, Hugli O, Tamchès E, et al. Oligoanalgesia in the emergency department: short-term beneficial effects of an education program on acute pain. Ann Emerg Med 2007;50:462-71.

4 Vazirani J, Knott JC. Mandatory pain scoring at triage reduces time to analgesia. Ann Emerg Med 2012;59:134-8.

5 Taylor SE, Taylor DMcD, Jao K, et al. Nurse-Initiated Analgesia pathway for paediatric patients in the emergency department: a clinical intervention trial. Emerg Med Australas 2013;25:316-23.

6 Schull MJ, Guttmann A, Leaver CA, et al. Prioritizing performance measurement for emergency department care: consensus on evidence-based quality of care indicators. CJEM 2011;13:300-9.

7 Taylor DMcD, Fatovich D, Finucci D, et al. Best-practice Pain Management in the Emergency Department: a cluster-randomised, controlled, intervention trial. Emerg Med Australas 2015;27:549-57.

8 Shill J, Taylor DMcD, Ngui B, et al. Factors associated with high levels of patient satisfaction with pain management. Acad Emerg Med 2012;19:1212-15.

9 Cinar O, Ernst R, Fosnocht D, et al. Geriatric patients May not experience increased risk of oligoanalgesia in the emergency department. Ann Emerg Med 2012;60:207-11.

10 Hansen $\mathrm{K}$, Thom $\mathrm{O}$, Rodda $\mathrm{H}$, et al. Impact of pain location, organ system and treating speciality on timely delivery of analgesia in emergency departments. Emerg Med Australas 2012;24:64-71.

11 Fosnocht DE, Heaps ND, Swanson ER. Patient expectations for pain relief in the ED. Am J Emerg Med 2004;22:286-8.

12 Fry $M$, Bennetts $S$, Huckson $S$. An Australian audit of ED pain management patterns. J Emerg Nurs 2011;37:269-74.
13 Liversidge $\mathrm{XL}$, Taylor DMcD, Liu B, et al. Variables associated with parent satisfaction with their child's pain management. Emerg Med Australas 2016;28:39-43.

14 Muntlin A, Carlsson M, Säfwenberg U, et al. Outcomes of a nurse-initiated intravenous analgesic protocol for abdominal pain in an emergency department: a quasi-experimental study. Int J Nurs Studies 2011;48:13-23.

15 Bijur PE, Latimer CT, Gallagher EJ. Validation of a verbally administered numerical rating scale of acute pain for use in the emergency department. Acad Emerg Med 2003; 10:390-2

16 Collins SL, Moore RA, McQuay HJ. The visual analogue pain intensity scale: what is moderate pain in millimetres? Pain 1997;72:95-7.

17 Alschuler KN, Jensen MP, Ehde DM. Defining mild, moderate, and severe pain in persons with multiple sclerosis. Pain Med 2012;13:1358-65.

18 Cordell WH, Keene KK, Giles BK, et al. The high prevalence of pain in emergency medical care. Am J Emerg Med 2002;20:165-9.

19 Bhakta HC, Marco CA. Pain Management: association with patient satisfaction among emergency department patients. J Emerg Med 2014;46:456-64.

20 Todd $\mathrm{KH}$, Sloan EP, Chen C, et al. Survey of pain etiology, management practices and patient satisfaction in two urban emergency departments. CJEM 2002;4:252-6.

21 Mills AM, Edwards JM, Shofer FS, et al. Analgesia for older adults with abdominal or back pain in emergency department. West J Emerg Med 2011;12:43-50.

22 Hwang $U$, Richardson LD, Harris $B$, et al. The quality of emergency department pain care for older adult patients. J Am Geriatr Soc 2010;58:2122-8.

23 Venkat A, Fromm C, Isaacs E, et al., on behalf of the SAEM Ethics Committee. An ethical framework for the management of pain in the emergency department. Acad Emerg Med 2013;20:716-23.

24 Singer AJ, Garra G, Chohan JK, et al. Triage pain scores and the desire for and use of analgesics. Ann Emerg Med 2008;52:689-95.

25 Body R, Kaide E, Kendal $S$, et al. Not all suffering is pain: sources of patients' suffering in the emergency department call for improvements in communication from practitioners. Emerg Med J 2015;32:15-20. 